\title{
Producing High Wettable Surface on Pure Titanium Sheets by Shot Peening for Bone Implant Applications
}

\author{
Chelamalasetti Pavan Satyanarayana ${ }^{1, *(\mathbb{D})}$, Lam Ratna Raju ${ }^{1(\mathbb{D})}$, Ravikumar Dumpala ${ }^{2}$, , Ratna Sunil \\ Buradagunta $^{3, * \text { (D) }}$ \\ 1 Department of Mechanical Engineering, Vignan's Foundation for Science, Technology \& Research, Vadlamudi 522213, \\ India; chpavansatyanarayana@gmail.com (C.P.S.), lamratnaraju@gmail.com (L.R.R.); \\ 2 Department of Mechanical Engineering, Visvesvaraya National Institute of Technology, Nagpur 440010, India; \\ ravikumardumpala@mec.vnit.ac.in (R.K.D.); \\ 3 Department of Mechanical Engineering, Bapatla Engineering College, Bapatla 522101, India; bratnasunil@gmail.com \\ (R.S.B.); \\ * Correspondence: bratnasunil@gmail.com (R.S.B.); chpavansatyanarayana@gmail.com (C.P.S.);
}

Scopus Author ID 35410353400

Received: 29.08.2021; Revised: 10.10.2021; Accepted: 14.10.2021; Published: 21.10.2021

\begin{abstract}
Pure titanium (Ti) sheets were subjected to shot peening to achieve grain refinement at the surface. Microstructural studies revealed significant grain refinement at the surface of the Ti sheet after shot peening. The affected thickness of the grain refined region was measured as $150 \mu \mathrm{m}$ at the crosssection. Due to the fine grain structure, higher hardness was measured for the processed surface. X-ray diffraction studies of the processed sample showed peak broadening for processed Ti due to shot peening. Wettability studies conducted by contact angle measurements clearly showed increased hydrophilicity for the processed $\mathrm{Ti}$ as reflected in the lower contact angles. Increased surface energy was calculated for the shot-peened $\mathrm{Ti}$, which can be attributed to the role of the increased fraction of grain boundaries due to microstructure modification. The results demonstrate the potential of the shot peening process to improve the surface wettability and further directly enhance the bioactivity of the Ti implant.
\end{abstract}

Keywords: shot peening; titanium; wettability; bioactivity; surface energy; grain refinement.

(C) 2021 by the authors. This article is an open-access article distributed under the terms and conditions of the Creative Commons Attribution (CC BY) license (https://creativecommons.org/licenses/by/4.0/).

\section{Introduction}

Titanium (Ti) and its alloys are the most widely used materials to manufacture orthopedic implants. Ti's mechanical properties are close to natural bone compared with other metallic implants, which reduces stress shielding problems [1]. Ti also exhibits non-magnetic nature, which allows MRI scanning of the patient having a Ti-based implant, which is not possible with steel base implants. Owing to its high corrosion resistance, Ti can sustain in the highly aggressive physiological environment for a longer time compared with steels and Cobased alloys [2-4]. However, Ti suffers from a lack of bioactivity, i.e., it exhibits bio-inert nature. For implants used in joint replacements such as hip joint or knee joint replacement, the implant surface that interacts with the bone tissue is desired to have higher bioactivity to promote strong bonding between the implant and the bone tissue. For example, in total hip joint replacement, the femoral stem of the hip joint must have a strong bonding with the femoral bone tissue. However, the acetabular cup and liner, femoral head, or ball do not require bioactivity but higher wear resistance. Whereas in bone fixing plates and screws, higher bioactivity is desired to promote a higher healing rate. 
The bioactivity of implants can be enhanced by adopting various strategies, as observed from the literature. A few examples are providing bioactive surface coatings, surface chemical treatments, and microstructural modifications [3-13]. Powder metallurgy, additive manufacturing, Laser surface treatment, etc., are a few processes used to develop Ti-based engineered medical implants [14-17]. Recently, several authors demonstrated the potential of microstructural modification by mechanical processing on enhancing the bioactivity of metallic implants. Among them, severe plastic deformation (SPD) techniques occupy the first place to alter the microstructure without affecting the geometry of the material. High strain is introduced into the material in SPD techniques, and through dynamic recrystallization, grain refinement is achieved [18]. Thirugnanam et al. [19] demonstrated improved bioactivity for groove pressed $\mathrm{Ti}$ due to the high surface energy obtained by grain refinement in $\mathrm{Ti}$. In our earlier study, Ti rods (solid and hollow) were subjected to equal channel angular pressing (ECAP) and due to obtained sub-micrometer structure, enhanced cell adhesion was observed [20]. Other reported works also clearly demonstrate that the refined microstructure enhances surface properties of Ti-based biomaterials [5,6].

Wettability is an essential property required for the implant surfaces to promote higher cell interactions at the implant-tissue interface. High wettable surfaces improve the deposition of mineral phases in the presence of the bio-environment. For example, surfaces with higher wettability promote higher biomineralization from the biological fluids in biomedical engineering and signal the primary cells to grow on the implant surface [21]. A higher level of cell response can be seen on the implants having refined microstructure [22]. Ti exhibits bioinert nature, depending on the targeted application, selectively the surface of Ti implant can be subjected to mechanical processing, and the bioactivity can be imparted. As the interactions between the implant and the local tissue are initiated from the implant's surface, surface engineering to alter the microstructure and surface properties of the implant to improve the tissue bonding ability is a viable strategy. Among the available surface treatments, shot peening is a simple and effective process in which the targeted surface is bombarded with several tiny shots [23]. Due to the compressive residual stresses resulting in shot peening, the component's fatigue life is increased [24]. Usually, shot peening is applied to the engineering components and surfaces to improve the components' life span and reduce the sudden failures during functioning $[25,26]$. On the other hand, a significant change also can be expected in the microstructure at the surface after shot peening. This effect is prominent with the increased size of the shots. Hence, the advantage in obtaining grain refinement in shot peening can be utilized to improve the surface properties of biomaterials. Therefore, in the present work, medical-grade $\mathrm{Ti}$ sheets were surface treated by shot peening to alter the surface microstructure and investigate the influence of shot peening on altering the surface hardness and wettability.

\section{Materials and Methods}

Commercially pure $\mathrm{Ti}(\mathrm{CP}-\mathrm{Ti})$ sheets of $2 \mathrm{~mm}$ thickness were procured from Venku Metals, India. Specimens of size 100 x $100 \mathrm{~mm}$ were prepared for shot peening experiments. Shot peening was conducted by placing the samples in a chamber and applying steel shots of diameter $2 \mathrm{~mm}$ with the help of compressed air. The pressurized air that passes through the nozzle colloid the surface with the steel shots supplied into the air stream. Figure 1 shows a schematic illustration of the shot peening process and the surface peening that induces compressive stresses at the surface of the workpiece. The processed samples were named as SP-Ti. 


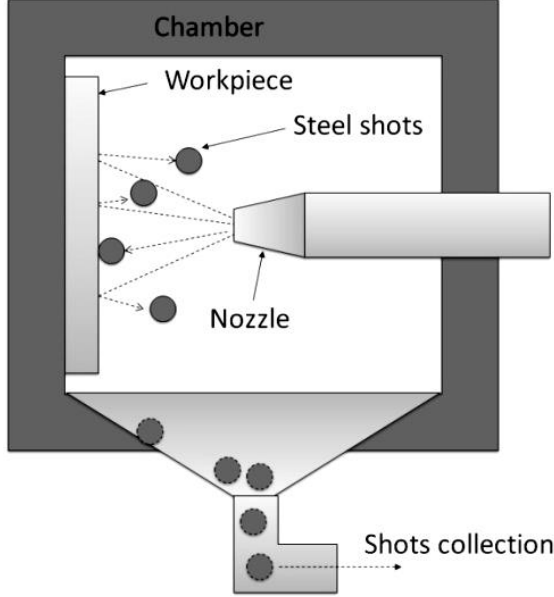

(a)

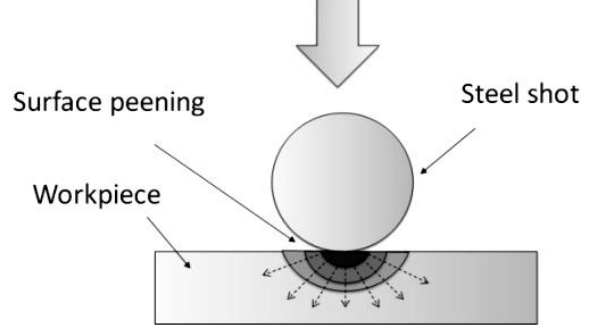

(b)

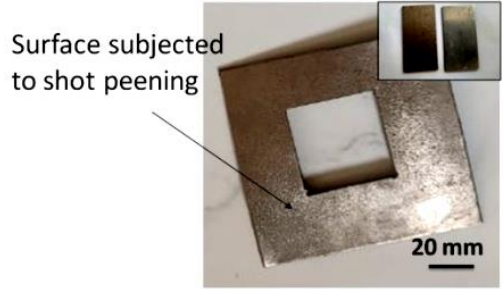

(c)

Figure 1.(a) schematic illustration of shot peening process, (b) inducing high compressive stresses from the striking shots, and (c) photograph showing the surface of SP-Ti (inset: samples of size 20 x 10 cut from SP-Ti).

X-Ray diffraction studies (XRD, D8, Bruker, USA) were carried out for both the SP$\mathrm{Ti}$ and $\mathrm{CP}-\mathrm{Ti}$ sheets for the $2 \theta$ range from 20 to $80^{\circ}$ with a step size of 0.05 . $\mathrm{CuK} \alpha$ radiation was used in the XRD analysis. The samples were then subjected to the standard polishing protocol for microstructural observations. The superfine polished surface of the samples was etched by using Kroll's agent and cleaned with ethanol. The optical microscope images were captured at different magnifications using an inverted optical microscope (Leica, Germany). The average grain size was measured by adopting the linear intercept method. A scanning electron microscope (SEM, TESCON, Czech Republic) attached with an energy dispersive Xray analysis (EDS) facility was used to observe the microstructure and chemical composition of the samples. The microhardness of the samples was measured by conducting indentation experiments using Vicker's microhardness tester using a diamond indenter at $100 \mathrm{~g}$ load. Measurements were obtained across the thickness to verify the effect of the shot peening on the microstructure modification from the surface to the inner regions of the processed Ti sheet in the thickness direction. Contact angles by using distilled water as the solvent were obtained for each sample. From the contact angles $(\theta)$, the surface energy of the samples $\left(E_{s}\right)$ was measured by considering the surface tension of distilled water $\left(E_{\mathrm{vl}}=72.8 \mathrm{~mJ} / \mathrm{m}^{2}\right)$ using the following equation [27].

$$
\mathrm{E}_{\mathrm{s}}=\mathrm{E}_{\mathrm{vl}} \cos \theta
$$

\section{Results and Discussion}

The main objective of the shot peening process is to induce compressive stresses in the surface of a metallic sheet or plate to achieve improved fatigue life. However, the repetitive impact of the shots introduces crystal imperfections and leads to a microstructural modification. The region that undergoes plastic deformation at a microscopic level at the surface of the workpiece due to the impact of the flying shots is limited to a few hundreds of micrometers. This is similar to the mechanism by which nanostructured surfaces of metals can be produced due to localized plastic deformation in surface mechanical attrition treatment (SMAT) [28]. However, the velocity with which the balls hit the workpiece's surface is lower than shot peening. However, in both the shot peening and SMAT processes, surface grain refinement is expected. Since the size of the balls is larger in SMAT, the depth of the affected surface is 
relatively higher than shot peening. Whereas in shot peening, the velocity of the shots impact the surface is higher than the size of balls used in SMAT but introduce microstructural modifications and increase the compressive stresses. Figure 2 compares the microstructure of $\mathrm{CP}-\mathrm{Ti}$ and SP-Ti at the cross-section. It is evident (Figure 2 (b)) from the observations that the layer of refined grain surface in SP-Ti. A magnified image (Figure 2(c)) of the cross-section shows refined grain region in SP-Ti up to $50 \mu \mathrm{m}$. Under the refined grain region, the presence of numerous twins can also be observed in the cross-section of SP-Ti (Figure 2(c)). Being an hcp metal, Ti usually undergoes plastic deformation by slip and twinning. Therefore, the appearance of twins is a common phenomenon when Ti undergoes plastic deformation. The depth of grain refinement region was observed as nonuniform at the cross-section of SP-Ti. This is due to the random bombardment of the shots on the surface of the Ti sheet during shot peening.
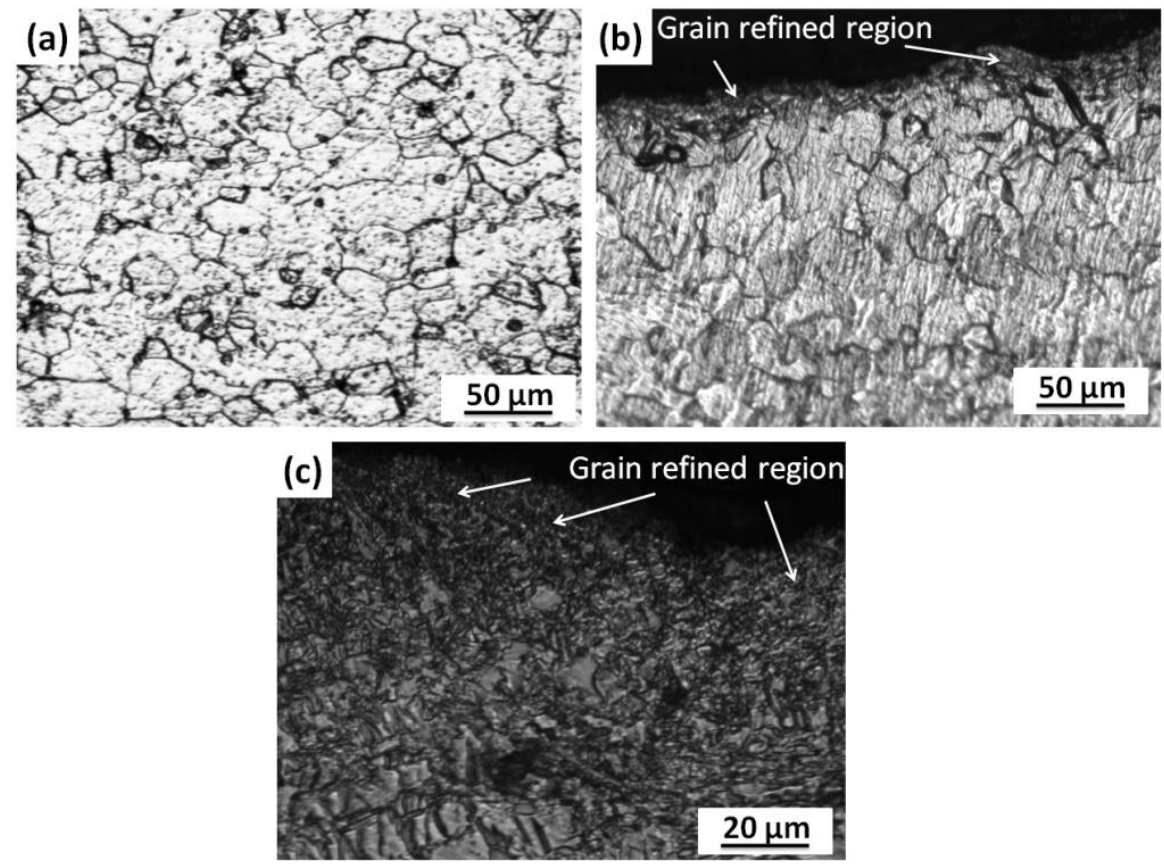

Figure 2. Optical microscope images of the samples: (a) CP-T, (b), and (c)cross-section of SP-Ti.

Figure 3 shows the XRD plots of the samples before and after shot peening. By comparing the normalized peaks from the $\mathrm{XRD}$, the textural changes induced by shot peening can be noticed. The peak relative intensities of (002), (102), (110), and (103) were significantly decreased, and the peak of (100) and (101) was significantly increased after shot peening. These changes strongly suggest the development of texture due to the plastic deformation at the surface of SP-Ti. Furthermore, the peak broadening after shot peening indicates the decreased crystallite size in SP-Ti, supported by the grain refinement at the surface of SP-Ti as observed from the microstructural studies. Figure 4 shows the comparison of hardness data of CP-Ti and SP-Ti. Due to the grain refinement, presence of more twins, and induced high compressive stresses in SP-Ti, higher average hardness $(269.5 \pm 13.4 \mathrm{Hv})$ was measured compared with CP$\mathrm{Ti}(196.2 \pm 7.8 \mathrm{Hv})$. The hardness distribution profile obtained on the surface and cross-section of SP-Ti explains the role of grain refinement achieved at the surface of the SP-Ti on enhancing the hardness. The cross-section profile shows a declining trend in hardness with the thickness away from the surface. 


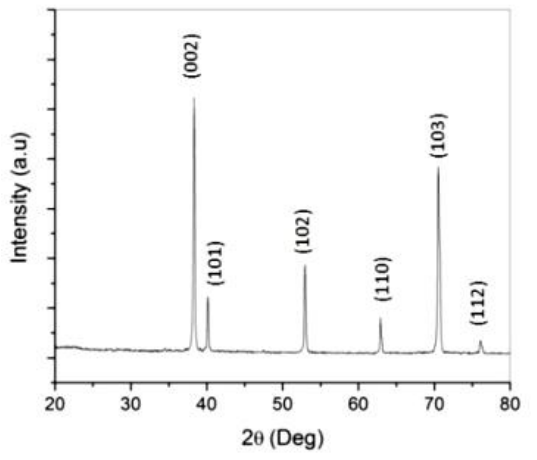

(a)

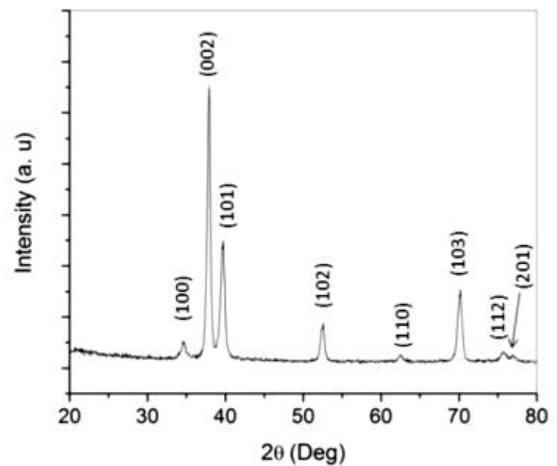

(b)

Figure 3. XRD patterns of the samples: (a) CP-Ti and (b) SP-Ti.

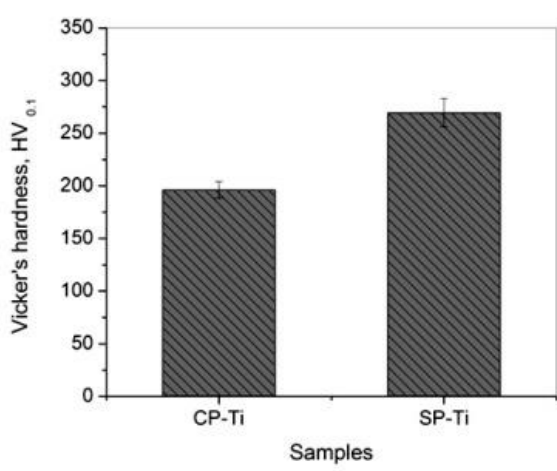

(a)

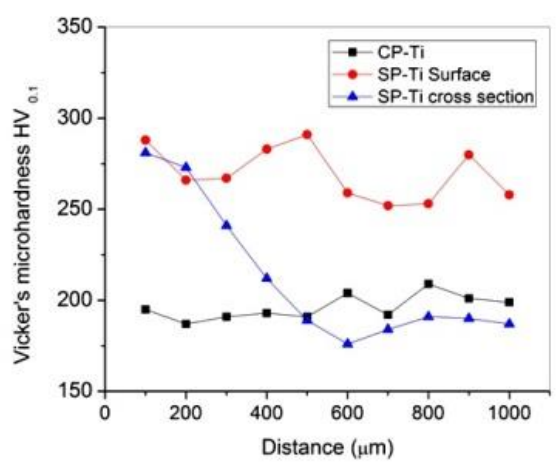

(b)

Figure 4. Microhardness measurements: (a) average hardness and (b) hardness distribution.
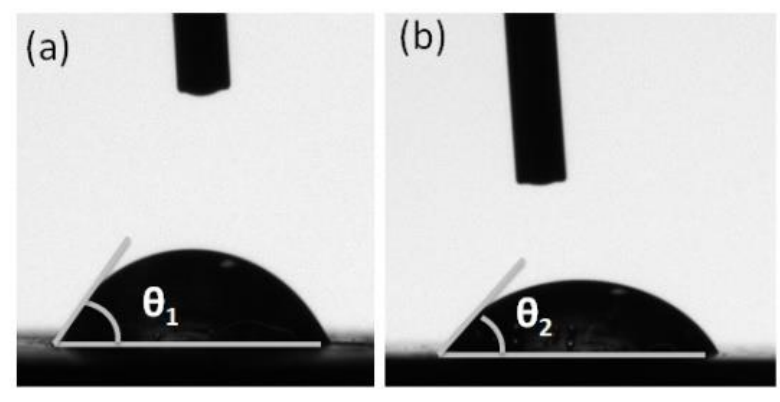

Figure 5. Photographs of water drop on the surface of the samples: (a) CP-Ti and (b) SP-Ti.

The photographs of water droplets on the surface of CP-Ti and SP-Ti during measuring contact angles are shown in Figure 5.

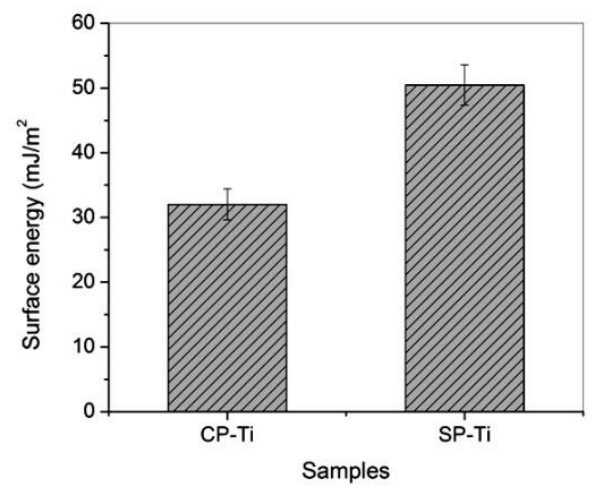

Figure 6. Surface energies of the samples calculated from water contact angles.

From the measured $\theta$ values $\left(\mathrm{CP}-\mathrm{Ti}=63.9 \pm 1.8^{\circ}\right.$ and $\left.\mathrm{SP}-\mathrm{Ti}=46.1 \pm 2.1^{\circ}\right)$, it is evident that the surface of SP-Ti is more hydrophilic compared with $\mathrm{CP}-\mathrm{Ti}$ as reflected in lower contact 
angles. Surfaces with lower water contact angles exhibit higher wettability, the desired property that promotes a higher level of cell adhesion on the implant surface.

Figure 6 shows the calculated surface energies of the samples. SP-Ti has shown higher surface energy compared with CP-Ti. With the grain refinement and presence of more twins at the surface of SP-Ti, the available fraction of grain boundary has been enormously increased. It is a well-understood phenomenon that the grain boundaries are considered as surface defects and associated with higher surface energies due to the imperfection in the crystal structure (pseudo crystal structure) [29]. With the development of new grains and twins due to shot peening in SP-Ti, more grain boundaries and twin boundaries also appear, which eventually increases the surface energy.

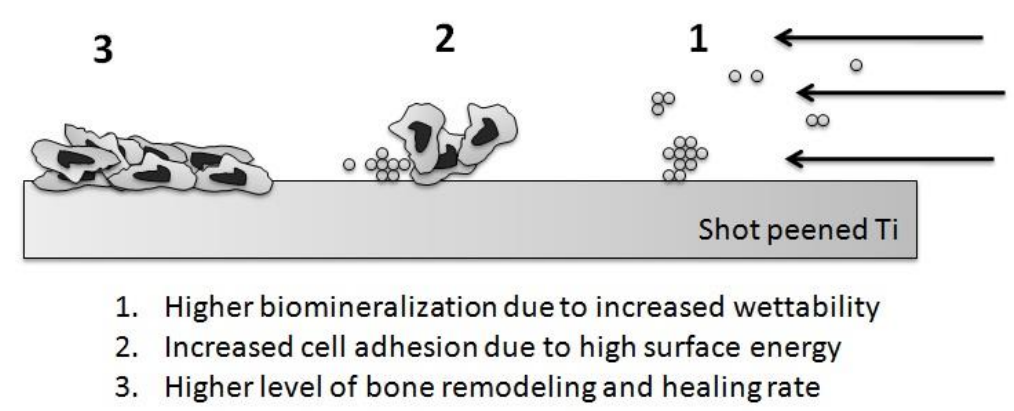

Figure 7. Schematic illustration of improved cell-implant interactions with increased wettability.

The thin layer $(50 \mu \mathrm{m})$ of refined grain surface of SP-Ti with higher surface energy accelerates the tissue-implant interactions by making the surface bioactive. Usually, when a material is used for bone implant applications, the formation of new bone follows the following major steps [23], as schematically illustrated in Figure 7.

i. Adsorption of protein from the surrounding bio-environment (blood plasma and tissue fluids) at the implant's surface.

ii. Movement of specific connective cells and inflammatory cells towards the implant's surface and releasing targeted specific matrix proteins.

iii. The approach of osteogenic cells to the implant's surface accelerated cell adhesion and bone remodeling at the tissue-implant interface.

The events above influence the implant acceptance by the local host and promote a higher healing rate. Among the sequence of events, the biomineralization step is crucial. A higher level of protein deposition and essential growth factors deposit on the implant's surface and strongly influence the healing rate [21]. Therefore, altering the surface of Ti to accelerate biomineralization helps to develop bioactive Ti-based implants. Surfaces with higher surface energy exhibit higher wettability [22]. Higher wettability promotes rapid biomineralization, and by doing so, a higher bone remodeling rate can be achieved. Furthermore, refined grain surfaces promote a higher level of cell adhesion and growth, as demonstrated by Thirugnanam et al. [19] on groove pressed Ti due to grain refinement. Similarly, Jojibabu et al. [20] produced fine-grained Ti rods by equal channel angular pressing (ECAP) and observed higher cell adhesion on ECAPed Ti compared with a base material. Therefore, it can be summarized that the fine grain structure with higher surface energy achieved in SP-Ti helps to develop Ti implants with higher bioactivity and increases the rate of new bone formation to achieve a better healing rate. 


\section{Conclusions}

Medical grade pure Ti sheets were subjected to shot peening by using $2 \mathrm{~mm}$ diameter steel shots. Grain refinement up to a thickness of $50 \mu \mathrm{m}$ was achieved at the cross-section, followed by several twins. XRD data revealed the texture change and confirmed the decreased crystallite size after shot peening. Due to the grain refinement and presence of twins, higher hardness was measured for the SP-Ti. Water contact angle measurements demonstrate the nature of higher hydrophilicity of SP-Ti. Surface energies calculated from the contact angles indicate higher surface energy for SP-Ti that promotes higher cell interactions at the surface of Ti. Hence, the results show that shot peening can produce surface grain refined Ti that exhibits higher wettability to promote better tissue-implant interactions to develop bioactive Ti-based implants.

\section{Funding}

This research received no external funding.

\section{Acknowledgments}

Thanks are due to Mr. B. Venkateswarlu, Assistant Professor, Dept of MME, IIIT Nuzvid, India and Dr. M. Ananda Rao, Principal Scientist, CSIR-NML Madras Complex, Chennai, India, for helping in material testing and characterization.

\section{Conflicts of Interest}

The authors declare no conflict of interest.

\section{References}

1. Zhang, L.C.; Chen, L.Y. A Review on Biomedical Titanium Alloys: Recent Progress and Prospect. Adv. Eng. Mater.2019, 21,https://doi.org/10.1002/adem.201801215.

2. Kaur, M.; Singh, K. Review on Titanium and Titanium Based Alloys as Biomaterials for Orthopaedic Applications. Mater. Sci. Eng. C 2019, 102, 844-862, https://doi.org/10.1016/j.msec.2019.04.064.

3. Geetha, M.; Singh, A.K.; Asokamani, R.; Gogi, A.K. Ti Based Biomaterials, the Ultimate Choice for Orthopaedic Implants - A Review. Prog. Mater. Sci. 2009, 54, 397425,https://doi.org/10.1016/j.pmatsci.2008.06.004.

4. Chen, L.Y.; Cui, Y.W.; Zhang, L.C. Recent Development in Beta Titanium Alloys for Biomedical Applications. Metals 2020, 10, https://doi.org/10.3390/met10091139.

5. Jemat, A.; Ghazali, M.J.; Razali, M.; Otsuka, Y. Surface Modifications and Their Effects on Titanium Dental Implants. Bio. Med. Research. Intl. 2015, 2015, https://doi.org/10.1155/2015/791725.

6. Truong, V.K.; Stuart, R.; Lapovok, R.; Estrin, Y.; Wang, J.Y.; Berndt, C.C.; Barnes, D.G.; Fluke, C.J.; Crawford, R.J.; Ivanova, E.P. Effect of Ultra Fine-Grained Titanium Surfaces on Adhesion of Bacteria. Appl. Microbiol. Biotechnol. 2009, 83, 925-937, https://doi.org/10.1007/s00253-009-1944-5.

7. Ratna Sunil, B.; Thirugnanam, A.; Chakkingal, U.; Sampath Kumar, T.S. Nano and Ultra Fine Grained Metallic Biomaterials by Severe Plastic Deformation Techniques. Mater. Technol. 2016, 31, 743755,https://doi.org/10.1080/10667857.2016.1249133.

8. Thomas, K.A.; Swati, D.; Sultana, N.; Sarkar, K.; Shubhabrata, D. Design of Ti Composite with Bioactive Surface for Dental Implant. Mater. Manuf. Proces. 2020, 3, 643-651, https://doi.org/10.1080/10426914.2020.1711927.

9. Yang, K.; Wang, J.; Tang, H.; Li, Y. Additive Manufacturing of In-Situ Reinforced Ti-35Nb-5Ta-7Zr (TNTZ) Alloy by Selective Electron Beam Melting (SEBM). J. Alloys Compd. 2020, 826, https://doi.org/10.1016/j.jallcom.2020.154178.

10. Yadav, P.; Saxena, K.K. Effect of Heat-Treatment on Microstructure and Mechanical Properties of Ti Alloys: An Overview. Mater. Today Proc. 2020, 26, 2546-2557. https://doi.org/10.1016/j.matpr.2020.02.541. 
11. Daniel, M.; Yordan, H.; Rolf, M.; Michael, K.; Johann, P.R.; Cyril, P.; Margarita, D.A. Influence of Surface Termination of Ultrananocrystalline Diamond Films Coated on Titanium on Response of Human Osteoblast Cells: A Proteome Study. Mater. Sci. Eng. C, 2021, 128, https://doi.org/10.1016/j.msec.2021.112289.

12. Alejandra, R.C.; Diego, T.; Belal, R.; Monica, O. H.; Maria, P. G.; José, A. C.; José, M. M.; Elisa, R. Bioactivity and Antibacterial Properties of Calcium- and Silver-Doped Coatings on 3D Printed Titanium Scaffolds. Surf. Coat. Technol. 2021, 421, https://doi.org/10.1016/j.surfcoat.2021.127476.

13. Nicholson, J.W. Titanium Alloys for Dental Implants: A Review. Prosthesis 2020, 2, 100-116, https://doi.org/10.3390/prosthesis2020011.

14. Romero-Resendiz, L.; Gómez-Sáez, P.; Vicente-Escuder, A.; Amigó-Borrás, V. Development of Ti-In alloys by powder metallurgy for application as dental biomaterial, J. Mater. Res. Technol. 2021, 11, 17191729,https://doi.org/10.1016/j.jmrt.2021.02.014.

15. Dzogbewu, T.C.; du Preez, W.B. Additive Manufacturing of Titanium-Based Implants with Metal-Based Antimicrobial Agents. Metals2021, 11, https://doi.org/10.3390/met11030453.

16. Mohazzab, B.F.; Jaleh, B.; Fattah-alhosseini, A.; Mahmoudi, F.; Momeni, A. Laser surface treatment of pure titanium: Microstructural analysis, wear properties, and corrosion behavior of titanium carbide coatings in Hank's physiological solution. Surfaces and Interfaces 2020, https://doi.org/10.1016/j.surfin.2020.100597.

17. Wang, Q.; Zhou, P.; Liu, S.; Attarilar, S.; Ma, R.L.; Zhong, Y.; Wang, L. Multi-Scale Surface Treatments of Titanium Implants for Rapid Osseointegration: A Review. Nanomaterials 2020, 10,https://doi.org/10.3390/nano10061244.

18. Valiev, R. Nanostructuring of metals by severe plastic deformation for advanced properties. Nature Mater.2004, 3, 511-516, https://doi.org/10.1038/nmat1180.

19. Thirugnanam, A.; Sampath Kumar, T.S.; Uday Chakkingal. Tailoring the bioactivity of commercially pure titanium by grain refinement using groove pressing, Mat. Sci. Eng. C2010, 30, 203208,https://doi.org/10.1016/j.msec.2009.10.002.

20. Jojibabu, P.; Sunil, B.R.; Kumar, T.S.S.; Chakkingal, U.; Nandakumar, V.; Doble, M. Wettability and In Vitro Bioactivity Studies on Titanium Rods Processed by Equal Channel Angular Pressing. Transactions of the Indian Institute of Metals 2013, 66, 299-304,https://doi.org/10.1007/s12666-013-0281-7.

21. Puleo, D.A.; Nanci, A. Understanding and controlling the bone-implant interface. Biomaterials 1999, 20, 2311-2321,https://doi.org/10.1016/s0142-9612(99)00160-x.

22. Zhang, L.; Webster, T.J. Nanotechnology and nanomaterials: Promises for improved tissue regeneration, Nano Today. 2009, 4, 66-80,https://doi.org/10.1016/j.nantod.2008.10.014.

23. Soyama, H.; Chighizola, C.R.; Hill, M.R. Effect of compressive residual stress introduced by cavitation peening and shot peening on the improvement of fatigue strength of stainless steel. Journal of Materials Processing Technology 2021, 288,https://doi.org/10.1016/j.jmatprotec.2020.116877.

24. Maleki, E.; Unal, O.; Reza Kashyzadeh, K.; Bagherifard, S.; Guagliano, M. A systematic study on the effects of shot peening on a mild carbon steel: Microstructure, mechanical properties, and axial fatigue strength of smooth and notched specimens. Applied Surface Science Advances 2021, 4,https://doi.org/10.1016/j.apsadv.2021.100071.

25. Khajehmirza, H.; Heydari Astaraee, A.; Monti, S.; Guagliano, M.; Bagherifard, S. A hybrid framework to estimate the surface state and fatigue performance of laser powder bed fusion materials after shot peening. Applied Surface Science 2021, 567,https://doi.org/10.1016/j.apsusc.2021.150758.

26. Qu, S.; Duan, C.; Hu, X.; Jia, S.; Li, X. Effect of shot peening on microstructure and contact fatigue crack growth mechanism of shaft steel. Materials Chemistry and Physics 2021, 274, https://doi.org/10.1016/j.matchemphys.2021.125116.

27. Wenzel, R.N. Resistance Of Solid Surfaces To Wetting By Water. Industrial \& Engineering Chemistry 1936, 28, 988-994, https://doi.org/10.1021/ie50320a024.

28. Lu, K.; Lu, J. Nanostructured surface layer on metallic materials induced by surface mechanical attrition treatment.Mater. Sci. Eng. A2004, 375-377, 38-45, https://doi.org/10.1016/j.msea.2003.10.261.

29. Sidney, H.A. Introduction to Physical Metallurgy.Tata McGraw Hill1997, 65. 